Article

\title{
Prevalence and Risk Factors of Intestinal Parasite Infections in Greek Swine Farrow-To-Finish Farms
}

\author{
Isaia Symeonidou ${ }^{1}$, Panagiotis Tassis ${ }^{2}{ }^{\circledR}$, Athanasios I. Gelasakis ${ }^{3}{ }^{\circledR}$, Eleni D. Tzika ${ }^{2}$ \\ and Elias Papadopoulos 1,* \\ 1 Laboratory of Parasitology and Parasitic Diseases, School of Veterinary Medicine, Faculty of Health Sciences, \\ Aristotle University of Thessaloniki, 54124 Thessaloniki, Greece; isaia@vet.auth.gr \\ 2 Farm Animals Clinic, School of Veterinary Medicine, Faculty of Health Sciences, \\ Aristotle University of Thessaloniki, 54627 Thessaloniki, Greece; ptassis@vet.auth.gr (P.T.); \\ eltzika@vet.auth.gr (E.D.T.) \\ 3 Laboratory of Anatomy and Physiology of Farm Animals, Department of Animal Science, \\ School of Animal Biosciences, Agricultural University of Athens, 11855 Athens, Greece; gelasakis@aua.gr \\ * Correspondence: eliaspap@vet.auth.gr
}

Received: 15 June 2020; Accepted: 7 July 2020; Published: 10 July 2020

check for updates

\begin{abstract}
Intestinal parasites, helminths, and protozoa challenge health and welfare of pigs and deteriorate the sustainability of swine farms leading to monetary losses. A multicentric survey was conducted for approximately one year. Overall, 1150 fecal samples were collected from eight intensive farms in Greece at regular intervals and examined by flotation and Ziehl-Neelsen techniques. Age, season, and time of last recorded antiparasitic treatment were assessed as possible risk factors using binary regression models. The overall prevalence of intestinal parasitism in pigs was $44.7 \%$. The most frequently detected parasites in the studied population were the protozoa Balantidium coli (37.8\%), followed by Entamoeba spp. (8.3\%), Cystoisospora suis (6.0\%), and the nematodes Ascaris suum $(3.7 \%)$, Trichuris suis (2.5\%), and Oesophagostomum spp. (1.4\%). Distribution of intestinal parasites in different age groups was as expected. In autumn, the prevalence of Balantidium coli infection enhanced whereas the prevalence of Entamoeba spp. and Cystoisospora suis infections increased in spring. Time of last recorded antiparasitic treatment influenced Balantidium coli and Trichuris suis infection levels. Our results demonstrated that swine intestinal parasitism in intensive farms of Greece seems to be relatively common and highlighted the importance of proper laboratory examinations, as well as the need for tailored made control programs.
\end{abstract}

Keywords: intestinal parasites; pigs; risk factors; Greece; swine farms

\section{Introduction}

The vast majority of swine farms in Greece are farrow-to-finish intensive conventional units, with their own feed mill. Pigs remain permanently housed and under controlled environmental conditions, usually on slatted or semi-slatted floor, with limited access to outdoor areas, and thus rare contact with soil. However, partial access of breeding stocks to outdoor areas at some points of production (e.g., gestation units) is the norm, therefore, animals can be exposed to parasites.

Pigs may harbor numerous intestinal parasites, most commonly protozoa and nematodes. Although the course of such parasitic infections is usually subclinical, sometimes, clinical infections may occur particularly in growing pigs [1,2]. Various intestinal parasites have been implicated as causative agents of intestinal disorders such as vomiting, diarrhea, enteritis, typhlocolitis, and rectal prolapse, as well as general symptoms (e.g., anemia) and lesions (e.g., 'white/milk spots' on the liver) [3,4]. Additionally, parasitized pigs tend to be more susceptible to infectious and non-infectious diseases, which undermine their health and welfare status [3,5]. 
In many cases, the actual prevalence, transmission dynamics, and effects of intestinal parasites in pigs' health, welfare, and production potential are underestimated. Moreover, there are well-known flaws and weaknesses of the commonly used preventive veterinary medicine programs in intensively reared pigs resulting from the scarcity of evidence-based antiparasitic protocols [6]. In modern conventional farms, parasitic diseases are not commonly diagnosed, and differential diagnosis of intestinal disorders rarely includes parasites as causative or contributing agents. This misperception is attributed to the notion that there are universally accepted antiparasitic programs, which sufficiently protect the animals, and the fact that parasitic infections are diagnosed more frequently in cases of extensively reared or organic swine farms $[1,7]$.

It has been well documented that swine parasitism results in major monetary losses worldwide mainly due to reduced nutritional conversion and growth rate $[1,2,5,8]$ and changes in body composition, i.e., less meat and heavier plucks [8,9]. It is noteworthy that some porcine parasites may pose a risk of infection to professionals involved in the value chain (e.g., farmers, veterinarians, and abattoir workers), either via direct contact or via exposure to contaminated environment $[10,11]$. The protozoon Balantidium coli can be transmitted from pigs to humans and act as an occasional pathogen $[12,13]$ while Entamoeba spp. of swine origin does not seem to have a zoonotic implication [14]. Cryptosporidium is another zoonotic protozoon of pigs, which can cause serious diarrhea, particularly in immunodeficient individuals and children [11,15], whereas, Ascaris suum and possibly Trichuris suis may have public health implications $[10,16]$.

To the best of our knowledge, there is a remarkable scarcity of large-scale, comprehensive studies on the occurrence and possible risk factors of pig intestinal parasitism in conventional swine farms in Greece. Therefore, the objectives of this repeated cross-sectional study were (i) to investigate the current epizootiological status of the major swine parasites, as has been shaped by the regularly applied antiparasitic programs in intensive farms in Greece the last decades; and (ii) to assess possible risk factors, which predispose to the aforementioned intestinal parasitic infections in intensive swine units.

\section{Results}

\subsection{Epizootiology of Intestinal Parasites in the Studied Population}

Diarrheic specimens were not observed in any of the age groups. The consistency of all stool specimens from all age groups, except from suckling piglets, was firm and the color was typical brown ranging from light brown to dark brown due to diet differences among groups. Fecal samples from suckling piglets were softer and of yellowish to light brown coloration due to diet (milk). In total, 44.7\% (514/1150) of the examined samples were found to excrete at least one parasitic element. Among them, 374 pigs (32.5\%) were found to be infected with only one parasite genera, while $112(9.7 \%), 24(2.1 \%)$, and $4(0.3 \%)$ pigs were harboring two, three and four different parasite genera, respectively. Overall, infected animals were present in all eight farms, whereas six different intestinal parasite species were identified. B. coli was the most prevalent parasite $(n=435$ pigs, $37.8 \%)$, followed by Entamoeba spp. $(n=95$ pigs, $8.3 \%)$, C. suis $(n=69$ pigs, $6.0 \%)$, A. suum $(n=42$ pigs, $3.7 \%)$, T. suis $(n=29$ pigs, $2.5 \%)$, and Oesophagostomum spp. ( $n=16$ pigs, $1.4 \%$ ) (Figures 1 and 2 ). The prevalence of the studied intestinal parasitic infections per group and per season is presented in Tables 1 and 2, respectively. 


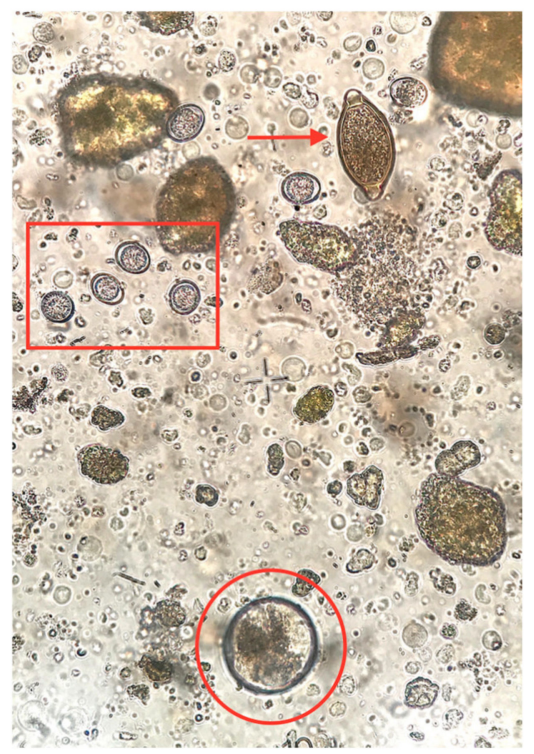

Figure 1. Various parasitic elements $(\times 400$ magnification) detected in pigs in Greece: Trichuris suis egg (arrow), Cystoisospora suis oocysts (rectangle), and Balanditium coli cyst (circle).

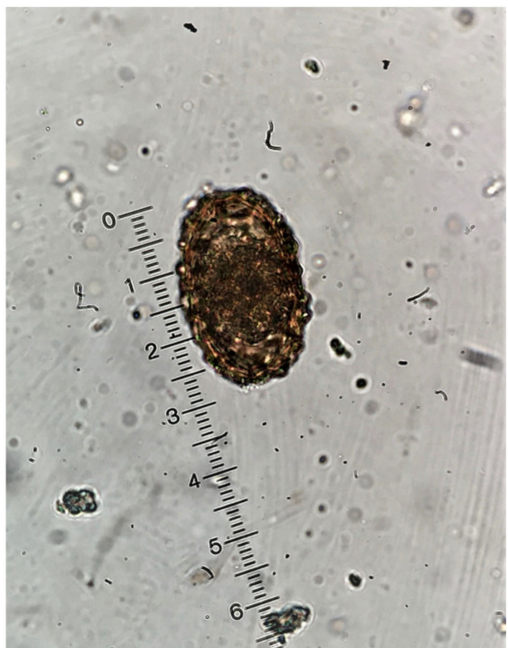

Figure 2. Ascaris suum egg as seen in the microscope ( $\times 400$ magnification).

Table 1. Prevalence of intestinal parasitic infections per group in the studied pig population (suckling piglets, weaners, growers, fatteners, sows, $n=230$ pigs per group, total $=1150$ pigs)

\begin{tabular}{ccccccc}
\hline Parasite & $\begin{array}{c}\text { Suckling } \\
\text { Piglets }\end{array}$ & Weaners & Growers & Fatteners & Sows & Total \\
\hline Balantidium coli & $6(2.6 \%)$ & $31(13.5 \%)$ & $86(37.4 \%)$ & $125(54.3 \%)$ & $187(81.3 \%)$ & $435(37.8 \%)$ \\
Entamoeba spp. & $0(0.0 \%)$ & $0(0.0 \%)$ & $3(1.3 \%)$ & $8(3.5 \%)$ & $84(36.5 \%)$ & $95(8.3 \%)$ \\
Cystoisospora suis & $44(19.1 \%)$ & $21(9.1 \%)$ & $0(0.0 \%)$ & $0(0.0 \%)$ & $4(1.7 \%)$ & $69(6.0 \%)$ \\
Ascaris suum & $0(0.0 \%)$ & $0(0.0 \%)$ & $2(0.9 \%)$ & $2(0.9 \%)$ & $38(16.5 \%)$ & $42(3.7 \%)$ \\
Trichuris suis & $0(0.0 \%)$ & $0(0.0 \%)$ & $1(0.5 \%)$ & $0(0.0 \%)$ & $28(12.2 \%)$ & $29(2.5 \%)$ \\
Oesophagostomum spp. & $0(0.0 \%)$ & $0(0.0 \%)$ & $2(0.9 \%)$ & $2(0.9 \%)$ & $12(5.2 \%)$ & $16(1.4 \%)$ \\
Single infection & $44(19.1 \%)$ & $48(20.9 \%)$ & $83(36.1 \%)$ & $119(51.7 \%)$ & $80(34.8 \%)$ & $374(32.5 \%)$ \\
Double infection & $3(1.3 \%)$ & $2(0.9 \%)$ & $4(1.7 \%)$ & $9(3.9 \%)$ & $94(40.9 \%)$ & $112(9.7 \%)$ \\
Triple infection & $0(0.0 \%)$ & $0(0.0 \%)$ & $1(0.4 \%)$ & $0(0.0 \%)$ & $23(10.0 \%)$ & $24(2.1 \%)$ \\
Quadriple infection & $0(0.0 \%)$ & $0(0.0 \%)$ & $0(0.0 \%)$ & $0(0.0 \%)$ & $4(1.7 \%)$ & $4(0.3 \%)$ \\
\hline
\end{tabular}


Table 2. Prevalence of intestinal parasitic infections in the studied pig population $(n=1150$ pigs) per season

\begin{tabular}{cccc}
\hline Parasite & $\begin{array}{c}\text { Autumn } \\
(\boldsymbol{n}=\mathbf{4 0 0 )}\end{array}$ & $\begin{array}{c}\text { Winter } \\
(\boldsymbol{n}=\mathbf{3 5 0 )}\end{array}$ & $\begin{array}{c}\text { Spring } \\
(\boldsymbol{n}=\mathbf{4 0 0 )}\end{array}$ \\
\hline Balantidium coli & $157(39.3 \%)$ & $141(40.3 \%)$ & $137(34.3 \%)$ \\
Entamoeba spp. & $25(6.3 \%)$ & $23(6.6 \%)$ & $47(11.8 \%)$ \\
Cystoisospora suis & $26(6.5 \%)$ & $13(3.7 \%)$ & $30(7.5 \%)$ \\
Ascaris suum & $13(3.3 \%)$ & $16(4.6 \%)$ & $13(3.3 \%)$ \\
Trichuris suis & $7(1.8 \%)$ & $9(2.6 \%)$ & $13(3.3 \%)$ \\
Oesophagostomum spp. & $0(0.0 \%)$ & $10(2.9 \%)$ & $6(1.5 \%)$ \\
\hline
\end{tabular}

\subsection{Effects of Risk Factors on Parasitic Infections}

The effects of the studied risk factors used as independent variables into the regression models (season, age, time passed since the last antiparasitic treatment, and farm) for the six parasite genera (Balantidium, Entamoeba, Cystoisospora, Ascaris, Trichuris, and Oesophagostomum) are summarized below (Table 3).

Table 3. Regression coefficients of the variables used in the models for the detected intestinal parasites

\begin{tabular}{|c|c|c|c|c|c|c|c|c|}
\hline & & P 1 & & $P$ & & Odds & $95 \%$ C.I & EXP(B) \\
\hline & & B $^{1}$ & S.E. ${ }^{2}$ & $P$ & & Ratio & Lower & Upper \\
\hline \multirow{10}{*}{ 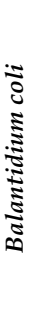 } & Autumn & 0.43 & 0.19 & 0.023 & & 1.53 & 1.06 & 2.21 \\
\hline & Winter & 0.15 & 0.22 & 0.477 & & 1.17 & 0.76 & 1.78 \\
\hline & Spring & \multicolumn{7}{|c|}{ Ref. } \\
\hline & Suckling piglets & -5.30 & 0.454 & 0 & & 0.01 & 0 & 0.01 \\
\hline & Weaners & -3.51 & 0.267 & 0 & \multirow{5}{*}{ Ref. } & 0.03 & 0.02 & 0.05 \\
\hline & Growers & -2.11 & 0.226 & 0 & & 0.12 & 0.08 & 0.19 \\
\hline & Fatteners & -1.39 & 0.222 & 0 & & 0.25 & 0.16 & 0.39 \\
\hline & Adult & & & & & & & \\
\hline & ATI (<120 days) & -0.65 & 0.223 & 0.004 & & 0.53 & 0.34 & 0.81 \\
\hline & ATI (>120 days) & \multicolumn{7}{|c|}{ Ref. } \\
\hline \multirow{5}{*}{ 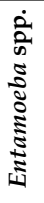 } & Autumn & -0.72 & 0.262 & 0.006 & \multirow{4}{*}{ Ref. } & 0.49 & 0.29 & 0.82 \\
\hline & Winter & -0.87 & 0.364 & 0.017 & & 0.42 & 0.21 & 0.86 \\
\hline & Spring & & & & & & & \\
\hline & ATI (<120 days) & -0.24 & 0.362 & 0.501 & & 0.78 & 0.39 & 1.59 \\
\hline & ATI (>120 days) & & & & \multicolumn{4}{|l|}{ Ref. } \\
\hline \multirow{5}{*}{ 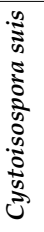 } & Autumn & -0.10 & 0.293 & 0.733 & & 0.91 & 0.51 & 1.61 \\
\hline & Winter & -0.65 & 0.373 & 0.083 & \multirow{3}{*}{ Ref. } & 0.52 & 0.25 & 1.09 \\
\hline & Spring & & & & & & & \\
\hline & ATI (<120 days) & -0.26 & 0.357 & 0.462 & & 0.77 & 0.38 & 1.55 \\
\hline & ATI (>120 days) & & & & \multicolumn{4}{|l|}{ Ref. } \\
\hline \multirow{5}{*}{ 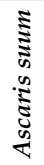 } & Autumn & 0.27 & 0.47 & 0.562 & \multirow{4}{*}{ Ref. } & 1.31 & 0.52 & 3.3 \\
\hline & Winter & -0.15 & 0.633 & 0.814 & & 0.86 & 0.25 & 2.98 \\
\hline & Spring & & & & & & & \\
\hline & ATI (<120 days) & -0.97 & 0.753 & 0.2 & & 0.38 & 0.09 & 1.67 \\
\hline & ATI (>120 days) & & & & \multicolumn{4}{|l|}{ Ref. } \\
\hline \multirow{5}{*}{ 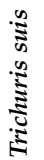 } & Autumn & 0.06 & 0.606 & 0.921 & \multirow{4}{*}{ Ref. } & 1.06 & 0.32 & 3.49 \\
\hline & Winter & -0.85 & 0.59 & 0.151 & & 0.43 & 0.14 & 1.36 \\
\hline & Spring & & & & & & & \\
\hline & ATI (<120 days) & -1.55 & 0.723 & 0.032 & & 0.21 & 0.05 & 0.88 \\
\hline & ATI (>120 days) & & & & \multicolumn{2}{|l|}{ Ref. } & & \\
\hline
\end{tabular}

1 B: Regression coefficient, ${ }^{2}$ S.E.: Standard error, ${ }^{3}$ C.I.: Confidence interval, ${ }^{4}$ Ref.: Reference category, ATI: Anthelmintic treatment interval.

\subsubsection{B. coli}

B. coli parasitism increased as age progressed. In detail, suckling piglets and weaners had a 200 ( $p \leq 0.001$, CI 95\%, 83.3 to 500.0) and a 33.3 ( $p \leq 0.001$, CI 95\%, 20.0 to 55.6) times, respectively, lower probability of B. coli infection in comparison to sows. Similarly, growers and fatteners were 
$8.3(p \leq 0.001$, CI 95\%, 5.3 to 13.0$)$ and 4.0 ( $p \leq 0.001$, CI 95\%, 2.6 to 6.2$)$ times, respectively, less likely to be infected by B. coli when compared to sows. Moreover, a higher likelihood of infection with B. coli was recorded in autumn (1.5 times, $p \leq 0.01$, CI 95\%, 1.1 to 2.2) than in spring. An anthelmintic treatment interval of less than 120 days was associated with a lower probability of $B$. coli infection (1.9 times, $p=0.004$, CI 95\%, 1.2 to 2.9 times). The effects of the variables used in the B. coli model are summarized in Table 3. The goodness-of-fit statistics in the B. coli model indicated good fit $\left[\chi^{2}\right.$ ( 8 d.f.) $=7.202, p=0.515]$. A significant predictive value for $B$. coli infection was indicated by the omnibus test of model coefficients [ $\chi^{2}$ (14 d.f.) $=487.938, p<0.001$ ]. Cox and Snell $R^{2}$, and Nagelkerke $R^{2}$ values were 0.346 and 0.471 , respectively.

\subsubsection{Entamoeba spp.}

Suckling and weaned piglets were not infected by Entamoeba spp. in any case. A lower probability of infection with Entamoeba spp. was recorded in autumn (2.0 times, $p=0.006$, CI 95\%, 1.2 to 3.4) and winter (2.4 times, $p=0.017$, CI 95\%, 1.2 to 4.9 ) than in spring. Table 3 shows the variables used for Entamoeba spp. model and their effects on Entamoeba spp. infection status. According to H-L test, the Entamoeba spp. model fitted well the data $\left[\chi^{2}\right.$ (8 d.f.) $\left.=6.922, p=0.545\right]$. Moreover, according to the omnibus test of coefficients the model was predictive of Entamoeba spp. infection [ $\chi^{2}$ (10 d.f.) $=47.350$, $p \leq 0.001$. Cox and Snell $R^{2}$, and Nagelkerke $R^{2}$ values were 0.040 and 0.093 , respectively.

\subsubsection{C. suis}

Growers and fatteners were not found to be infected by C. suis in any case, whereas only four cases oocysts of $C$. suis were detected in sows. The likelihood of $C$. suis infection tended to be lower (ca. 1.9 times) in winter than in spring ( $p=0.083$, CI 95\%, 0.92 to 4.0 ); however, a significant difference was not concluded. The model provided a good fit to the data with the H-L test being insignificant $\left[\chi^{2}\right.$ (8 d.f.) $\left.=6.054, p=0.641\right]$. Moreover, according to the omnibus test of coefficients, the model was predictive of $C$. suis infection $\left[\chi^{2}(10\right.$ d.f. $\left.)=28.279, p \leq 0.01\right]$. Cox and Snell $R^{2}$, and Nagelkerke $R^{2}$ values were 0.024 and 0.067 , respectively.

\subsubsection{A. suum}

Suckling and weaned piglets were not infected by A. suum in any case, and for that reason age was not used as a risk factor in the model. The effects of season and time passed since the last antiparasitic treatment were not significant. H-L test was statistically insignificant indicating that the model fits the data well $\left[\chi^{2}\right.$ ( 8 d.f. $\left.)=1.492, p=0.993\right]$. Furthermore, according to the omnibus test of coefficients the model had a significant predictive value of $A$. suum infection $\left[\chi^{2}(10\right.$ d.f. $\left.)=48.792, p \leq 0.001\right]$. Cox and Snell $R^{2}$, and Nagelkerke $R^{2}$ values were 0.042 and 0.154 , respectively.

\subsubsection{T. suis}

Suckling piglets, weaners, and fatteners were not infected by T. suis in any case, whereas, in only one case T. suis eggs were identified in growers. The possibility of T. suis infection was 4.7 times lower for pigs with treatment intervals $<120$ days in comparison to those with treatment intervals $>120$ days ( $p=0.032$, CI 95\%, 1.1 to 19.6). Table 3 summarizes the effect size of the variables used into the T. suis model. The H-L goodness-of-fit test in the T. suis model indicated good fit $\left[\chi^{2}\right.$ ( 8 d.f. $)=1.843$, $p=0.985]$. A significant predictive value for T. suis infection was indicated by the omnibus test of model coefficients $\left[\chi^{2}(10\right.$ d.f. $\left.)=43.380, p<0.001\right]$. Cox and Snell $R^{2}$, and Nagelkerke $R^{2}$ values were 0.037 and 0.176 , respectively.

\subsubsection{Oesophagostomum spp.}

Suckling piglets and weaners were not infected by Oesophagostomum spp. in any case, whereas only in two cases Oesophagostomum spp. eggs were found in both growers and fatteners. The model for 
the assessment of Oesophagostomum spp. infection did not fit the data well and therefore, its results cannot be considered reliable.

\section{Discussion}

The aim of this extensive study was to evaluate the prevalence and intensity of pig parasitesunder the pressure of regular antiparasitic treatments in intensive conventional units in Greece. Additionally, a second objective was to assess the risk factors involved and display their potential interactions in view of creating a clearer picture of swine intestinal parasitism in Greece.

In total, the prevalence of intestinal infection with at least one parasite was ca. $45 \%$ (514/1150 pigs). Similar prevalence estimates have been recorded in previous studies conducted in other European countries. These studies have demonstrated that intestinal protozoa and helminths are commonly detected in swine farms in Germany [17,18], the Netherlands [19], the Nordic countries [5], Poland [20], and Switzerland [11] with reported prevalence, though ranging significantly among different countries. Evidently, in the present study, single infections were more frequent $(32.5 \%, n=374$ pigs) than multiple infections $(12.1 \%, n=140$ pigs). Moreover, protozoan infections were more prevalent $(51.8 \%, n=596$ pigs) compared to helminthic ones $(7.5 \%, n=87$ pigs), which is in accordance with the findings of Barbosa et al. [21].

B. coli was identified in all age groups and was the most commonly observed parasite in the studied swine population with a mean prevalence of $37.8 \%$. This prevalence rate is within the range of the expected average prevalence reported in other large-scale surveys, which was from $30.6 \%$ to $57.1 \%$ of the examined pigs $[2,11,22]$. Regarding its taxonomy, although it was nominated, based on morphological differences, that isolates from pigs (Balantidium suis) were different species [23], genetic analysis of isolates from gorillas, humans, and pigs elucidated that only one species infects warm-blooded animals [24]. Pigs, along with wild boars, remain the main reservoirs of this cosmopolitan protozoon, which attracts interest due to its zoonotic implication [25]. Transmission from pigs to humans has been documented [12,13] and people working in proximity to pigs have a higher risk of acquiring balantidiosis [26]. In humans, these ciliates are opportunistic parasites and in immunocompromised individuals the disease may be severe [25], while in pigs they normally are non-pathogenic [26]. In some cases, $B$. coli has been previously implicated as an underlying factor of swine colitis, although this role has not been fully clarified [4]. Regarding risk factors, B. coli parasitism increased as age progressed. Similarly, Hindsbo et al. [22] recorded that the prevalence estimates significantly increased from 57\% in suckling piglets to $100 \%$ in pigs older than 1 month and Morris et al. [27] reported that adult swine were more likely to be infected by this protozoon when compared to suckling piglets, weaners, growers, and fatteners. Correspondingly, Damriyasa and Bauer [18] also reported an age-related increase of balantidiosis in pigs. Furthermore, a higher likelihood of infection with B. coli was recorded in autumn than in spring. This can be presumably attributed to the fact that $B$. coli cysts survive best in humid ambience protected by direct sunlight [28]. Notably, the administration of an anthelmintic treatment in time interval of less than 4 months was associated with a ca. 2 times lower probability of $B$. coli infection. It has been established that helminths mediate generalized immunosuppression that abates immunity against protozoa [29]. It is therefore safe to speculate that the timely elimination of helminths alters the balantidiosis dynamics pattern in favor of the host.

Other protozoan parasites found in our study were Entamoeba spp. ( $n=95$ pigs, 8.3\%). A study in Germany has recorded a quite similar prevalence of $14.0 \%$ for Entamoeba spp. infections in farrow-to-finish swine farms [18]. Entamoeba spp. in pigs are mostly harmless and not of epidemiological relevance in Europe [14] since pigs are not considered a reservoir of Entamoeba histolytica for humans [4]. In this study, the frequency of amoebae infection was higher in sows than growers and fatteners, which agrees with the findings by Damriyasa and Bauer, who surveyed swine farms in Germany [18]. Furthermore, our results suggested that pigs reared in autumn and winter had a lower probability of infection with Entamoeba spp. 
Coccidia affected $6.0 \%$ of the examined animals ( $n=69$ pigs). Although several species of the genera Eimeria and Cystoisospora can infect pigs, C. suis (syn. Isospora suis) is the predominant coccidium [30,31]. C. suis may cause transient diarrhea, which is often implicated by secondary pathogens such as bacteria and viruses [32], thus resulting in weight loss and managerial costs [33]. Additionally, this protozoon can lead to possible alterations of intestinal epithelium and gut microbiota and consequent diminished nutrient absorption $[4,33,34]$. This apicomplexan protozoon affects mainly suckling piglets, which are unable to mount an adequate primary immune response [31,35]. Therefore, the increased prevalence of $C$. suis infections in our study, reported in suckling piglets followed by weaners, was an expected finding.

In detail, approximately 1 out of $5(19.1 \%)$ suckling piglets and 1 out of $10(9.1 \%)$ weaners were found to be infected; whereas, only in four cases was C. suis infection found in sows. Age-dependence of $C$. suis infections has been confirmed by other surveys in Europe, which have reported an increasing immunity by age against $C$. suis $[5,11,20,30,36]$. The recorded prevalence for $C$. suis in suckling piglets vary from $<1 \%$ to $>40 \%$ (e.g., $10.0 \%$ in Germany [18], $12.8 \%$ in Switzerland [11], 20.9\% in Southern Germany [36], 42.9\% in Poland [20] and for the Nordic countries: Denmark 19.5\%; Finland 4.5\%; Iceland $31.8 \%$; Norway $0.3 \%$ and Sweden $20.1 \%$ ) [5]. The discrepancy in infection intensity with some of aforementioned studies might be explained by the fact that toltrazuril, an effective coccidiostat that suppresses oocyst excretion and enhances piglet health in cases of experimental infections [37] and in the field [38], was administered per os at the first days of age in all farms that were included in the current study. Moreover, a factor with potential effect on C. suis infection could be the season, however, this effect was not concluded by the analysis of our dataset. A rise in temperature after the cold winter season in Greece and a relative high humidity are considered favorable climatic conditions for increasing oocyst sporulation [39] and this may account for the relatively higher prevalence of coccidiosis recorded in spring. In other animals, such as goats [40] and broiler chicks [41], similar patterns for coccidial infections being detected more frequently in spring than in winter have been established.

Cryptosporidium spp. oocysts were not detected in the present study. Accordingly, in a large-scale survey in Germany, where feces of pigs were examined for a period of 10 years, oocysts of this protozoon were not found [42]. It should be highlighted that a very low number of oocysts are excreted in pigs' feces, which accounts for the decreased sensitivity of microscopy for identification of this protozoon [43].

Regarding helminths, the species A. suum and T. suis and Oesophagostomum were detected. These nematodes have global distribution and occur in all kind of production systems [16]. High prevalence and infection intensity of intestinal nematodes are recorded in traditional and organic swine farms as opposed to low levels observed in intensive swine production units [42,44-46].

It should be noted that the host-specific status of both A. suum and T. suis are being debated $[10,16]$. A. suum is in close relation to Ascaris lumbricoides which affects approximately 1.2 billion people around the world. In the same frame, T. suis has been linked to Trichuris trichiura, that affects 795 million humans [47]. Experiments have confirmed that both of these nematodes can cross-infect pigs and humans $[48,49]$. Moreover, studies using credible molecular tools revealed the presence of shared cytochrome c oxidase subunit 1 (cox1) haplotypes between Ascaris of human and porcine origin [50,51]. Correspondingly, concerning T. suis, sequence analysis of the Internal Transcribed Spacer 2 (ITS-2) region of sympatric worms [52] and of the ITS region of eggs from worms collected from non-human primates and pigs [53] demonstrated that although Trichuris of the two hosts represent two different species, T. suis infection may be a zoonosis. Whether these two species are swine-specific pathogens or potentially zoonotic ones remains to be established by sophisticated molecular tools [10].

A. suum is the most prevalent helminth in pigs and its prevalence varies depending on farm management practices and geographical regions $[20,44,46]$. The mean prevalence of $A$. suum recorded in the present study (3.7\%) was low, although it should be stressed that the actual infection rate might be much higher. A crucial feature of porcine ascaridiosis, which should be taken into consideration, 
is that a large proportion of pigs with latent infection do not excrete eggs in their feces while their serological response results are positive, thus, the actual infection rate is often underestimated [54].

Pigs infected with $A$. suum have reduced villar-height to crypt-depth ratio in the intestinal mucosa [55] and consequently display reduced feed utilization and impaired lactase activity in their gut [56]. Moreover, the hepato-tracheal migration of the larvae causes injury and subsequent inflammatory response leading to the formation of the characteristic white spots in the liver of infected pigs [57] as well as to the induction of respiratory distress accompanied by short dry coughs or even severe dyspnea in some cases [58].

As it was expected, A. suum eggs were not detected in suckling piglets and weaners due to the long prepatent period of this nematode [59]. In this study, the prevalence rate was lower for growers and fatteners than sows $(0.9 \%$ in growers, $0.9 \%$ in fatteners, and $16.5 \%$ in sows). A survey in Denmark reported a similar pattern for $A$. suum infection, where the highest prevalence of parasitism by A. suum in industrialized swine farms was recorded in sows. An explanation for this infection pattern, according to the authors, is that no transmission occurs in the pens of growers and fatteners although the pens are contaminated [60]. This has been attributed to the lack of high relative humidity in indoor housing units [60], which is a prerequisite for egg embryonation and survival [61]. It has been demonstrated that desiccation causes the eggs to collapse before becoming infective [60]. On the other hand, the contamination is high under favorable environmental conditions that facilitate egg survival (e.g., in the outdoor areas of the pens) [62]. In addition, A. suum eggs that survive remain viable and infective for up to at least nine years [63] and therefore infections build up in sows as age progresses.

T. suis infection likelihood is directly linked to the housing system and although this nematode is widespread amongst pigs, it is sporadically found under intensive swine farming systems [5,11,44]. This is in accordance with the results of the present study where the total prevalence of the pig whipworm in all age groups was $2.5 \%$.

Clinically evident cases of trichurosis in pigs, characterized by mucous diarrhea, are scarce and the underdiagnosed subclinical infections cause reduced growth rate [64]. Of note, T. suis interferes with the structural architecture and function of the large intestine and alters the porcine colon microbiota, thus increasing susceptibility to secondary pathogens $[65,66]$. In detail, a study on germ-free pigs has demonstrated that infection with $T$. suis acts as an immune modulating factor and enhances the pathology of Campylobacter jejuni [67]. In the same context, Shin et al. [68] observed, in a pig experimental model, that $C$. jejuni was pathogenic only in the concurrent presence of T. suis. Moreover, the swine whipworm has been suggested to offer an entry point for agents of the swine dysentery complex [3]. Another experiment in pigs displayed that whipworm-induced immunosuppression of the intestinal mucosa to resident microbiota contributed to the establishment of necrotic proliferative colitis [69].

In the current study, all T. suis cases were reported in sows with the exception of one case which was observed in growers. This predominant occurrence of T. suis in adult pigs has been confirmed in other studies as well $[5,20]$. The prevalence of trichurosis is higher in adult pigs as a result of the long prepatent period of this nematode [59] and its resistant eggs, which maintain their infectivity and viability for up to 11 years [63,70]. Interestingly, the probability of $T$. suis infection was 4.7 times lower for pigs with treatment intervals $<4$ months. This result indicates that anthelmintic drugs in sows feed can induce lower whipworm load if administered regularly at $<4$-month intervals.

Oesophagostomum spp. larvae were identified only in one farm ( $n=16$ pigs, $1.4 \%)$. A low intensity of parasitism is expected for these nematodes since it is known that Oesophagostomum free-living larvae cannot survive during the warm and dry summer [71], which is the case in Greece. Furthermore, infections occurred more frequently in sows $(5.2 \%)$ than in growers $(0.9 \%)$ and fatteners $(0.9 \%)$. This distribution type is characteristic for Oesophagostomum spp. and has been attributed to the weak immunogenicity of these parasites [44] that results in higher worm burdens in adult animals $[5,20]$. In our study, it is impossible to draw safe conclusions regarding risk factors and prevalence of Oesophagostomum spp. infections by age due to the low number of cases. 
Results of the present study support the observation that the total elimination of intestinal parasitism in pigs is difficult to accomplish, even if regular and systematic antiparasitic prophylaxis is implemented. This can be attributed to many factors: (i) longevity and the subsequent probability of re-infection of breeding animals, e.g., lactating sows, that act as reservoirs of parasites for other age groups [2,21]; (ii) possible weaknesses of the commonly used treatments schemes in intensively raised pigs [6] that lie upon the application of in-feed preventive substance administration, independent of sows' bodyweight differences among age groups, that could cause under-dosing; (iii) inefficiency of prophylactic schemes which could be attributed to long time intervals (e.g., exceeding 6 months) between administration time points, in sows feed, that could create an 'unprotected time window' in breeding stock's life; and (iv) the re-occurrence of nematodes in intensive pig rearing units, which is associated with the increased viability of the highly resistant $A$. suum and T. suis eggs [63].

In addition to a preventive program, administered at time periods that do not exceed 4 months, it is advisable to take caution regarding a proper facilities sanitation plan in such confined units (regular feces removal where applicable, and proper cleaning and disinfection schemes), the reduction of crate-to-crate contamination carried on boots or clothing, the avoidance of pets and rodents, which act as mechanical transmitters, as all these are critical points of prevention of intestinal parasitic infection outbreaks in swine farms. Undertaking such actions will reduce the infectivity of the environment, thus the parasitic burden will be minimized $[4,6]$.

\section{Materials and Methods}

\subsection{Sampling Process}

The samplings took place between August 2017 and June 2018. All animals were apparently healthy, i.e., absence of obvious clinical signs prior to sampling and originated from eight intensive farrow-to-finish farms of Northern Greece. Fresh fecal samples were collected with a gloved hand individually during defecation to avoid feces contamination. In total, three samplings were performed in each farm approximately every 3 months, during a study period of 10 months to encompass seasonal variation. The same number of specimens was collected in each sampling occasion from randomly selected animals of all the groups in each of the studied farms, as follows: 10 samples from sows ( 5 in gestation and 5 in lactation), and 10 samples per group from suckling piglets (up to 4 weeks of age), weaners (4-10 weeks of age), growers (10-16 weeks of age), and fatteners (16 to 22-24 weeks of age). Thus, 50 samples were collected during each sampling occasion, resulting in a total of 150 specimens from each farm for the total study period ( 3 samplings/farm) except from one farm where only two samplings were feasible. Consequently, a total of 1150 fecal samples were included in the study.

The capacity of conventional farms that were enrolled in the study, varied from approximately 250 to 1000 sows (from first to sixth parity). Breeding was performed with artificial insemination in the gestation unit and access to external areas was permitted after ultrasonographic confirmation of gestation on the fourth week after insemination. All participating farms applied preventive antiparasitic treatments on a regular basis in breeding stocks and suckling piglets. The norm was the administration of a macrocyclic lactone (i.e., ivermectin) in sows' feed twice ( 7 farms) or three times ( $1 \mathrm{farm})$ per year, as well as in the feed of 10-12 weeks old growers (every 3 and 4 months in 4 farms and 4 farms, respectively). Additionally, in all farms, a coccidiostat (i.e., toltrazuril) was used per os at suckling piglets the first three days of age. Animals were randomly selected and information regarding season, age, and time period since the last antiparasitic treatment were registered for each sampling occasion. Specimens were placed individually in plastic containers, labeled, stored at $2-6{ }^{\circ} \mathrm{C}$ and transferred to the Laboratory of Parasitology and Parasitic Diseases of the School of Veterinary Medicine in Thessaloniki, where they were processed within $48 \mathrm{~h}$. 


\subsection{Coprological Methods Used}

Initially, each specimen was macroscopically examined to specify the macroscopic appearance of feces (consistency, color, etc.) and to detect the possible presence of adult nematodes. Thereafter, for each sample, the flotation technique was carried out as described by Faust et al. [72]. In brief, approximately $1 \mathrm{~g}$ of feces was diluted with tap water, passed into a centrifuge tube through a sieve (no. 150) and centrifuged at $200 \times \mathrm{g}$ for $3 \mathrm{~min}$. The supernatant was discarded and $\mathrm{ZnSO}_{4}$ solution $(33.2 \% w / v$, specific weight 1.3$)$ was added to the sediment. The sediment was thoroughly diluted and $\mathrm{ZnSO}_{4}$ solution was added to just over the top of the tube so as to form a meniscus. A cover slip was placed on the top of the meniscus and following centrifugation of the tube at $150 \times \mathrm{g}$ for $1 \mathrm{~min}$, the cover slip was removed, placed on a microscope slide and examined under the optical microscope at $\times 100$ and $\times 400$ magnification.

For detection of Cryptosporidium spp. oocysts, approximately $1 \mathrm{~g}$ of feces was diluted in tap water, passed through a sieve (no. 150) and centrifuged at $200 \times \mathrm{g}$ for $3 \mathrm{~min}$. The supernatant was discarded and drops of the aqueous sediment were coated on slides, the smears were stained with the Ziehl-Neelsen method [73] and examined under the optical microscope at $\times 1000$ magnification.

Coproculture was conducted for obtaining infective larvae and identifying Strongylida eggs to the genus level. Parasitic elements were identified based on morphological characteristics [74,75]. A pig was considered infected if at least one parasitic element (oocyst, cyst, egg, larva) was observed.

\subsection{Data Handling-Statistical Analyses}

Six binary logistic regression models were used to test the possible relationship between sampling season (three levels; autumn, winter, spring), age (five levels; sows, suckling piglets, weaners, growers, fatteners), anthelmintic treatment interval (two levels; $\leq 4$ months and $>4$ months), and farm (eight levels; farms 1 to 8 ) and the likelihood that a pig is infected with the most prevalent parasites, namely, A. suum, T. suis, C. suis, B. coli, Entamoeba spp., and Oesophagostomum spp.

Statistical significance of individual predictors was tested using the Wald $\chi^{2}$ statistic of their regression coefficients $(\beta \mathrm{s})$. Goodness-of-fit for each individual model was assessed using the Hosmer-Lemeshow (H-L) test, as well as Cox and Snell $R^{2}$ and Nagelkerke $\mathrm{R}^{2}$ indices.

\subsection{Ethics Approval and Consent to Participate}

The study was conducted in compliance with the national animal welfare regulations, i.e., the Presidential Decree 56/13 “Bringing Greek legislation into line with Directive 2010/63/EC of the European Parliament and of the Council of 22nd September 2010 (L 276/33/20.10.2010) regarding the protection of animals used for experimental and other scientific purposes". The applied diagnostic veterinary procedures are not within the context of relevant $\mathrm{EU}$ legislation for animal experimentations (Directive 86/609/EC) and may be performed in order to diagnose animal diseases and improve animal welfare. No suffering was caused during sample collection. Consent was ensured by farm owners.

\section{Conclusions}

To the best of our knowledge, this is the first time the prevalence of intestinal parasitism of pigs reared in conventional intensive Greek swine farms is assessed. Our observations suggest that intestinal parasitism in Greek swine farms is present and should not be underestimated when planning preventive measures to mitigate the occurrence of pathogens at a farm level, even though the likelihood of severe clinical disease is moderate to low under current farm conditions. Moreover, intestinal parasites should be considered in the differential diagnosis of intestinal disorders as underlying factors or co-infection intestinal pathogens, even in swine farms with an ongoing preventive antiparasitic program. The presence of parasite genera with zoonotic potential indicates that professionals in the Greek pig industry may be at risk of exposure to them. 
Author Contributions: Conceptualization, I.S. and P.T.; Methodology, I.S.; Software, A.I.G.; Formal analysis, A.I.G.; Investigation, I.S.; Data curation, A.I.G., I.S., and P.T.; Writing-original draft preparation, I.S. and P.T.; Writing-review and editing, I.S., P.T., A.I.G., E.D.T., and E.P.; Supervision, E.P. All authors have read and agreed to the published version of the manuscript.

Funding: This research received no external funding.

Conflicts of Interest: The authors declare no conflict of interest.

\section{References}

1. Joachim, A.; Dülmer, N.; Daugschies, A.; Roepstorff, A. Occurrence of helminthes in pig fattening units with different management systems in Northern Germany. Vet. Parasitol. 2001, 96, 135-146. [CrossRef]

2. Weng, Y.B.; Hu, Y.J.; Li, Y.; Li, B.S.; Lin, R.Q.; Xie, D.H.; Gasser, R.B.; Zhu, X.Q. Survey of intestinal parasites in pigs from intensive farms in Guangdong Province, People's Republic of China. Vet. Parasitol. 2005, 127, 333-336. [CrossRef] [PubMed]

3. Greve, J.H. Internal parasites: Helminths. In Diseases of Swine, 10th ed.; Zimmerman, J.J., Karriker, L.A., Ramirez, A., Schwartz, K.J., Stevenson, G.W., Eds.; Wiley-Blackwell: West Sussex, UK, 2012; pp. 908-920.

4. Lindsay, D.S.; Dubey, J.P.; Santín-Durán, M.; Fayer, R. Coccidia and other Protozoa. In Diseases of Swine, 10th ed.; Zimmerman, J.J., Karriker, L.A., Ramirez, A., Schwartz, K.J., Stevenson, G.W., Eds.; Wiley-Blackwell: West Sussex, UK, 2012; pp. 895-907.

5. Roepstorff, A.; Nilsson, O.; Oksanen, A.; Gjerde, B.; Richter, S.H.; Ortenberg, E.; Christensson, D.; Martinsson, K.B.; Bartlett, P.C.; Nansen, P.; et al. Intestinal parasites in swine in the Nordic countries: Prevalence and geographical distribution. Vet. Parasitol. 1998, 76, 305-319. [CrossRef]

6. Vandekerckhove, E. The Use of Serology in the Control of Ascaris Suum Infections in Pigs. Ph.D. Thesis, School of Veterinary Medicine, Ghent, Belgium, 2018.

7. Papatsiros, V.; Tassis, P.; Christodoulopoulos, G.; Boutsini, S.; Tsirigotakis, G.; Tzika, E. Health and Production of Greek Organic Pig Farming: Current situation and perspectives. J. Hell. Vet. Med. Soc. 2017, 63, 37-44. [CrossRef]

8. Pedersen, S.; Saeed, I.; Michaelsen, K.F.; Friis, H.; Murrell, K.D. Impact of protein energy malnutrition on Trichuris suis infection in pigs concomitantly infected with Ascaris suum. Parasitology 2002, 124, 561-568. [CrossRef]

9. Knecht, D.; Popiołek, M.; Zaleśny, G. Does meatiness of pigs depend on the level of gastro-intestinal parasites infection? Prev. Vet. Med. 2011, 99, 234-239. [CrossRef] [PubMed]

10. Nejsum, P.; Betson, M.; Bendall, R.P.; Thamsborg, S.M.; Stothard, J.R. Assessing the zoonotic potential of Ascaris suum and Trichuris suis: Looking to the future from an analysis of the past. J. Helminthol. 2012, 86, 148-155. [CrossRef]

11. Schubnell, F.; von Ah, S.; Graage, R.; Sydler, T.; Sidler, X.; Hadorn, D.; Basso, W. Occurrence, clinical involvement and zoonotic potential of endoparasites infecting Swiss pigs. Parasitol. Int. 2016, 65, 618-624. [CrossRef]

12. Sharma, S.; Harding, G. Necrotizing lung infection caused by the protozoan Balantidium coli. Can. J. Infect. Dis. 2003, 14, 163-166. [CrossRef]

13. Ferry, T.; Bouhour, D.; De Monbrison, F.; Laurent, F.; Dumouchel-Champagne, H.; Picot, S.; Piens, M.A.; Granier, P. Severe peritonitis due to Balantidium coli acquired in France. Eur. J. Clin. Microbiol. Infect. Dis. 2004, 23, 393-395. [CrossRef]

14. Daugschies, A. Protozoen Infektionen des Schweines. In Veterinärmedizinische Parasitologie, 6th ed.; Schnieder, T., Ed.; Parey: Stuttgart, Germany, 2006; pp. 359-408.

15. Xiao, L. Molecular epidemiology of cryptosporidiosis: An update. Exp. Parasitol. 2010, 124, 80-89. [CrossRef] [PubMed]

16. Roepstorff, A.; Mejer, H.; Nejsum, P.; Thamsborg, S.M. Helminth parasites in pigs: New challenges in pig production and current research highlights. Vet. Parasitol. 2011, 180, 72-81. [CrossRef]

17. Joachim, A.; Daugschies, A. Endoparasites in swine in different age groups and management systems. Berl. Munch. Tierarztl. Wochenschr. 2000, 113, 129-133. [PubMed]

18. Damriyasa, I.M.; Bauer, C. Prevalence and age-dependent occurrence of intestinal protozoan infections in suckling piglets. Berl. Munch. Tierarztl. Wochenschr. 2006, 119, 287-290. [PubMed] 
19. Eijck, I.A.; Borgsteede, F.H. A survey of gastrointestinal pig parasites on free-range, organic and conventional pig farms in The Netherlands. Vet. Res. Commun. 2005, 29, 407-414. [CrossRef] [PubMed]

20. Kochanowski, M.; Karamon, J.; Dąbrowska, J.; Dors, A.; Czyżewska-Dors, E.; Cencek, T. Occurrence of Intestinal Parasites in Pigs in Poland-The Influence of Factors Related to the Production System. J. Vet. Res. 2017, 61, 459-466. [CrossRef] [PubMed]

21. Barbosa, A.S.; Bastos, O.M.P.; Dib, L.V.; de Siqueira, M.P.; Cardozo, M.L.; Ferreira, L.C.; Chaves, W.T.; Fonseca, A.B.M.; Uchôa, C.M.A.; Amendoeira, M.R.R. Gastrointestinal parasites of swine raised in different management systems in the State of Rio de Janeiro, Brazil. Pesq. Vet. Bras. 2015, 35, 941-946. [CrossRef]

22. Hindsbo, O.; Nielsen, C.V.; Andreassen, J.; Willingham, A.L.; Bendixen, M.; Nielsen, M.A.; Nielsen, N.O. Age-dependent occurrence of the intestinal ciliate Balantidium coli in pigs at a Danish research farm. Acta Vet. Scand. 2000, 41, 79-83.

23. McDonald, J.D. On Balantidium coli (Malmsten) and Balantidium suis (sp. nov.) with an account of their neuromotor apparatus. Univ. Cal. Pub. Zool. 1922, 20, 243-300.

24. Ponce-Gordo, F.; Fonseca-Salamanca, F.; Martínez-Díaz, R.A. Genetic Heterogeneity in Internal Transcribed Spacer Genes of Balantidium coli (Litostomatea, Ciliophora). Protist 2011, 162, 774-794. [CrossRef]

25. Ponce-Gordo, F.; Jirků-Pomajbíková, K. Balantidium coli. In Global Water Pathogens Project; Rose, J.B., Jiménez-Cisneros, B., Eds.; Michigan State University Press: East Lansing, MI, USA, 2017; pp. 3-14.

26. Schuster, F.L.; Visvesvara, G.S. Amebae and ciliated protozoa as causal agents of waterborne zoonotic disease. Vet. Parasitol. 2004, 126, 91-120. [CrossRef] [PubMed]

27. Morris, R.G.; Jordan, H.E.; Luce, W.G.; Coburn, T.C.; Maxwell, C.V. Prevalence of gastrointestinal parasitism in Oklahoma swine. Am. J. Vet. Res. 1984, 45, 2421-2423.

28. Schuster, F.L.; Ramirez-Avila, L. Current world status of Balantidium coli. Clin. Microbiol. Rev. 2008, 21, 626-638. [CrossRef]

29. Ezenwa, V.O.; Jolles, A.E. From Host Immunity to Pathogen Invasion: The effects of helminth coinfection on the dynamics of microparasites. Integr. Comp. Biol. 2011, 51, 540-551. [CrossRef]

30. Mundt, H.C.; Cohnen, A.; Daugschies, A.; Joachim, A.; Prosl, H.; Schmäschke, R.; Westphal, B. Occurrence of Isospora suis in Germany, Switzerland and Austria. J. Vet. Med. B. Infect. Dis. Vet. Public Health 2005, 52, 93-97. [CrossRef] [PubMed]

31. Worliczek, H.L.; Buggelsheim, M.; Saalmüller, A.; Joachim, A. Porcine isosporosis: Infection dynamics, pathophysiology and immunology of experimental infections. Wien. Klin. Wochenschr. 2007, 119, 33-39. [CrossRef]

32. Chae, C.; Kwon, D.; Kim, O.; Min, K.; Cheon, D.S.; Choi, C.; Kim, B.; Suh, J. Diarrhoea in nursing piglets associated with coccidiosis: Prevalence, microscopic lesions and coexisting microorganisms. Vet. Rec. 1998, 143, 417-420. [CrossRef]

33. Shrestha, A.; Abd-Elfattah, A.; Freudenschuss, B.; Hinney, B.; Palmieri, N.; Ruttkowski, B.; Joachim, A. Cystoisospora suis-A Model of Mammalian Cystoisosporosis. Front. Vet. Sci. 2015, 2, 68. [CrossRef]

34. Komatsu, T.; Matsubayashi, M.; Murakoshi, N.; Sasai, K.; Shibahara, T. Retrospective and Histopathological Studies of Entamoeba spp. and Other Pathogens Associated with Diarrhea and Wasting in Pigs in Aichi Prefecture, Japan. Jpn. Agric. Res. Q. 2019, 53, 59-67. [CrossRef]

35. Koudela, B.; Kucerová, S. Role of acquired immunity and natural age resistance on course of Isospora suis coccidiosis in nursing piglets. Vet. Parasitol. 1999, 82, 93-99. [CrossRef]

36. Wieler, L.H.; Ilieff, A.; Herbst, W.; Bauer, C.; Vieler, E.; Bauerfeind, R.; Failing, K.; Klös, H.; Wengert, D.; Baljer, G.; et al. Prevalence of enteropathogens in suckling and weaned piglets with diarrhoea in southern Germany. J. Vet. Med. B. Infect. Dis. Vet. Public Health 2001, 48, 151-159. [CrossRef]

37. Joachim, A.; Mundt, H.C. Efficacy of sulfonamides and Baycox ${ }^{\circledR}$ against Isospora suis in experimental infections of suckling piglets. Parasitol. Res. 2011, 109, 1653-1659. [CrossRef]

38. Kreiner, T.; Worliczek, H.L.; Tichy, A.; Joachim, A. Influence of toltrazuril treatment on parasitological parameters and health performance of piglets in the field-An Austrian experience. Vet. Parasitol. 2011, 183, 14-20. [CrossRef]

39. Rodríguez-Vivas, R.I.; Domínguez-Alpizar, J.L.; Torres-Acosta, J.F. Epidemiological factors associated to bovine coccidiosis in calves (Bos indicus) in a subhumid tropical climate. Rev. Biomed. 1996, 7, 211-218.

40. Balicka-Ramisz, A.; Ramisz, A.; Vovk, S.; Snitynskyj, V. Prevalence of coccidia infection in goats in Western Pomerania (Poland) and West Ukraine Region. Ann. Parasitol. 2012, 58, 167-171. 
41. Awais, M.M.; Akhtar, M.A.; Muhammad, F.; Anwar, M.I. Seasonal prevalence of coccidiosis in industrial broiler chickens in Faisalabad, Pakistan. Trop. Anim. Health Prod. 2012, 44, 323-328. [CrossRef]

42. Raue, K.; Heuer, L.; Böhm, C.; Wolken, S.; Epe, C.; Strube, C. 10-year parasitological examination results (2003 to 2012) of faecal samples from horses, ruminants, pigs, dogs, cats, rabbits and hedgehogs. Parasitol. Res. 2017, 116, 3315-3330. [CrossRef]

43. Rzeżutka, A.; Kaupke, A.; Kozyra, I.; Pejsak, Z. Molecular studies on pig cryptosporidiosis in Poland. Pol. J. Vet. Sci. 2014, 17, 577-582. [CrossRef]

44. Nansen, P.; Roepstorff, A. Parasitic helminthes of the pig: Factors influencing transmission and infection levels. Int. J. Parasitol. 1999, 29, 877-891. [CrossRef]

45. Carstensen, L.; Vaarst, M.; Roepstorff, A. Helminth infections in Danish organic swine herds. Vet. Parasitol. 2002, 106, 253-264. [CrossRef]

46. Katakam, K.K.; Thamsborg, S.M.; Dalsgaard, A.; Kyvsgaard, N.C.; Mejer, H. Environmental contamination and transmission of Ascaris suum in Danish organic pig farms. Parasit. Vectors 2016, 9, 80. [CrossRef]

47. De Silva, N.R.; Brooker, S.; Hotez, P.J.; Montresor, A.; Engels, D.; Savioli, L. Soil-transmitted helminth infections: Updating the global picture. Trends Parasitol. 2003, 19, 547-551. [CrossRef]

48. Takata, I. Experimental infection of man with Ascaris of man and the pig. Kitasato Arch. Exp. Med. 1951, 23, $49-59$.

49. Galvin, T.J. Development of human and pig Ascaris in the pig and rabbit. J. Parasitol. 1968, 54, $1085-1091$. [CrossRef] [PubMed]

50. Peng, W.D.; Yuan, K.; Hu, M.; Zhou, X.M.; Gasser, R.B. Mutation scanning-coupled analysis of haplotypic variability in mitochondrial DNA regions reveals low gene flow between human and porcine Ascaris in endemic regions of China. Electrophoresis 2005, 26, 4317-4326. [CrossRef]

51. Betson, M.; Halstead, F.D.; Nejsum, P.; Imison, E.; Khamis, I.S.; Sousa-Figueiredo, J.C.; Rollinson, D.; Stothard, J.R. A molecular epidemiological investigation of Ascaris on Unguja, Zanzibar using isoenyzme analysis, DNA barcoding and microsatellite DNA profiling. Trans. R. Soc. Trop. Med. Hyg. 2011, 105, 370-379. [CrossRef] [PubMed]

52. Nissen, S. Morphological and Genetic Diversity of Whipworms (Trichuris spp.) Recovered from Pigs and Humans. Master's Thesis, University of Copenhagen, Copenhagen, Denmark, 2009.

53. Cutillas, C.; Callejón, R.; de Rojas, M.; Tewes, B.; Ubeda, J.M.; Ariza, C.; Guevara, D.C. Trichuris suis and Trichuris trichiura are different nematode species. Acta Trop. 2009, 111, 299-307. [CrossRef]

54. Roepstorff, A. Natural Ascaris suum infections in swine diagnosed by coprological and serological (ELISA) methods. Parasitol. Res. 1998, 84, 537-543. [CrossRef]

55. Stephenson, L.S.; Pond, W.G.; Nesheim, M.C.; Krook, L.P.; Crompton, D.W.T. Ascaris suum: Nutrient absorption, growth, and intestinal pathology in young pigs experimentally infected with 15-day-old larvae. Exp. Parasitol. 1980, 49, 15-25. [CrossRef]

56. Forsum, E.; Nesheim, M.C.; Crompton, D.W.T. Nutritional aspects of Ascaris infection in young protein-deficient pigs. Parasitology 1981, 83, 497-512. [CrossRef]

57. Ronéus, O. Studies on aetiology and pathogenesis of white spots in the liver of pigs. Acta Vet. Scand. 1966, 7 (Suppl. 16), 1-112.

58. Yoshihara, S.; Nakagawa, M.; Suda, H.; Ikeda, K.; Hanashiro, K. White spots of the liver in pigs experimentally infected with Ascaris suum. Natl. Inst. Anim. Health Q. 1983, 23, 127-137.

59. Deplazes, P.; Eckert, J.; von Samson-Himmelstjerna, G.; Zahner, H. Lehrbuch der Parasitologie für Tiermedizin, 3rd ed.; Enke Verlag: Stuttgart, Germany, 2013.

60. Roepstorff, A. Helminth surveillance as a prerequisite for anthelmintic treatment in intensive sow herds. Vet. Parasitol. 1997, 73, 139-151. [CrossRef]

61. Wharton, D.A. Ascaris sp.: Water loss during dessication of embryonating eggs. Exp. Parasitol. 1979, 48, 398-406. [CrossRef]

62. Larsen, M.N.; Roepstorff, A. Seasonal variation in development and survival of Ascaris suum and Trichuris suis eggs on pastures. Parasitology 1999, 119, 209-220. [CrossRef]

63. Mejer, H.; Roepstorff, A. Long-term survival of Ascaris suum and Trichuris suis eggs in relation to pasture management. In Proceedings of the 23rd International Conference of the World Association for the Advancement of Veterinary Parasitology, Buenos Aires, Argentina, 21-25 August 2011; AAPAVET: Buenos Aires, Argentina, 2011; p. 113. 
64. Stewart, T.B.; Hoyt, P.G. Internal parasites. In Diseases of Swine, 9th ed.; Straw, B.E., Zimmerman, J.J., D'Allaire, S., Taylor, D.J., Eds.; Blackwell Publishing: Ames, IA, USA, 2006; pp. 901-914.

65. Thomsen, L.E.; Bach Knudsen, K.E.; Hedemann, M.S.; Roepstorff, A. The effect of dietary carbohydrates and Trichuris suis infection on pig large intestine tissue structure, epithelial cell proliferation and mucin characteristics. Vet. Parasitol. 2006, 142, 112-122. [CrossRef] [PubMed]

66. Li, R.W.; Wu, S.; Li, W.; Navarro, K.; Couch, R.D.; Hill, D.; Urban, J.F., Jr. Alterations in the porcine colon microbiota induced by the gastrointestinal nematode Trichuris suis. Infect. Immun. 2012, 80, 2150-2157. [CrossRef] [PubMed]

67. Mansfield, L.S.; Gauthier, D.T.; Abner, S.R.; Jones, K.M.; Wilder, S.R.; Urban, J.F. Enhancement of disease and pathology by synergy of Trichuris suis and Campylobacter jejuni in the colon of immunologically naive swine. Am. J. Trop. Med. Hyg. 2003, 68, 70-80. [CrossRef]

68. Shin, J.L.; Gardiner, G.W.; Deitel, W.; Kandel, G. Does whipworm increase the pathogenicity of Campylobacter jejuni? A clinical correlate of an experimental observation. Can. J. Gastroenterol. 2004, 18, 175-177. [CrossRef]

69. Mansfield, L.S.; Urban, J.F., Jr. The pathogenesis of necrotic proliferative colitis in swine is linked to whipworm induced suppression of mucosal immunity to resident bacteria. Vet. Immunol. Immunopathol. 1996, 50, 1-17. [CrossRef]

70. Burden, D.J.; Hammet, N.C.; Brookes, P.A. Field observations on the longevity of Trichuris suis ova. Vet. Rec. 1987, 121, 43. [CrossRef] [PubMed]

71. Roepstorff, A.; Murrell, K.D. Transmission dynamics of helminth parasites of pigs on continuous pasture: Oesophagostomum dentatum and Hyostrongylus rubidus. Int. J. Parasitol. 1997, 27, 553-562. [CrossRef]

72. Faust, E.C.; D'Antonio, J.S.; Odom, V.; Miller, M.J.; Peres, C.; Sawitz, W.; Walker, J.H. A critical study of clinical laboratory techniques for the diagnosis of protozoan cysts and helminth eggs in feces. Am. J. Trop. Med. Hyg. 1938, 18, 169-183. [CrossRef]

73. Henriksen, S.A.; Pohlenz, J.F.L. Staining of Cryptosporidia by a modified Ziehl-Neelsen technique. Acta Vet. Scand. 1981, 22, 594-596. [PubMed]

74. Taylor, M.A.; Coop, R.L.; Wall, R.L. Veterinary Parasitology, 3rd ed.; Blackwell Publishing Ltd.: Oxford, UK, 2007.

75. Zajac, A.M.; Conboy, G.A. Veterinary Clinical Parasitology, 8th ed.; Wiley Blackwell: West Sussex, UK, 2012. 